Article

\title{
A Novel Analog Front End with Voltage-Dependent Input Impedance and Bandpass Amplification for Capacitive Biopotential Measurements
}

\author{
Hajime Nakamura ${ }^{1}$, Yuichiro Sakajiri ${ }^{1}$, Hiroshi Ishigami ${ }^{1}$ and Akinori Ueno ${ }^{2, *(D)}$ \\ 1 Master's Program in Electrical and Electronic Engineering, Graduate School of Engineering, Tokyo Denki \\ University, Tokyo 120-8551, Japan; uenolab_nakamura@uenolab.jp (H.N.); 18KMJ15@ms.dendai.ac.jp (Y.S.); \\ 19KMJ03@ms.dendai.ac.jp (H.I.) \\ 2 Department of Electrical and Electronic Engineering, Tokyo Denki University, Tokyo 120-8551, Japan \\ * Correspondence: ueno@mail.dendai.ac.jp; Tel.: +81-3-5284-5404
}

Received: 26 March 2020; Accepted: 24 April 2020; Published: 27 April 2020

\begin{abstract}
This paper proposes a novel analogue front end (AFE) that has three features: voltage-dependent input impedance, bandpass amplification, and stray capacitance reduction. With a view to applying the AFE to capacitive biopotential measurements (CBMs), the three features were investigated separately in a schematic and mathematical manner. Capacitive electrocardiogram (cECG) or capacitive electromyogram (cEMG) measurements using the AFE were performed in low-humidity conditions (below 35\% relative humidity) for a total of seven human subjects. Performance evaluation of the AFE revealed the following: (1) the proposed AFE in cECG measurement with 1.70-mm thick clothing reduced the baseline recovery time and root mean square voltage of respiratory interference in subjects with healthy-weight body mass index (BMI), and increased R-wave amplitude for overweight-BMI subjects; and (2) the proposed AFE in cEMG measurement of biceps brachii muscle yielded stable electromyographic waveforms without the marked DC component for all subjects and a significant $(p<0.01)$ increase in the signal-to-noise ratio. These results indicate that the proposed AFE can provide a feasible balance between sensitivity and stability in CBMs, and it could be a versatile replacement for the conventional voltage follower used in CBMs.
\end{abstract}

Keywords: capacitive biopotential measurement; non-contact measurement; electrocardiogram; electromyogram; analog front end; voltage-dependent resistance

\section{Introduction}

As population aging is accelerating globally and high medical costs are becoming increasingly problematic, the concept of smart healthcare is gaining attention as an effective solution [1,2]. Smart healthcare is a health service system that uses technology such as wearable devices, the Internet of Things (IoT), and mobile internet to dynamically access information, connect people, materials and institutions related to healthcare, and then actively manage and respond to medical ecosystem needs in an intelligent manner [3]. Smart healthcare has the potential to provide comprehensive patient care in diverse environments including hospitals and home treatment [4]. Thus, smart healthcare is expected to reduce medical costs, ameliorate the quality of life and enrich the user experience [5].

There is growing interest in various types of wearable devices that detect physiological information such as the electrocardiogram (ECG) and electromyogram (EMG) [6,7]. Previously reported wearables devices include patches [8], wristbands [9-11], earrings [12], eyeglasses [13], fabric [14] and garments [15-17]. In clinical practice, the Holter monitor is well-known among existing and commercially available wearable devices; it is able to record ECG continuously for 24 to $48 \mathrm{~h}$. The Holter 
monitor is a useful device to diagnose cardiovascular diseases, which is the main cause of death around the world. However, as is the case with existing biopotential measurement devices, the Holter monitor requires direct contact of adhesive electrodes with the skin. Attachment for a long time or frequent detachment of the electrodes can cause skin allergy or inflammation as the measurement period gets longer. Thus, they are not suitable for monitoring over a prolonged period. In this context, capacitive biopotential measurement (CBM) has been studied because of its ability to detect biopotential without the direct contact of electrodes with the skin.

CBM is a measurement method that exploits capacitive coupling, which is comprised of skin, insulator (or cloth), and electrodes. Some researchers have already successfully used CBM in detecting ECG [18,19], EMG [20-22] and electroencephalograms (EEG) [23-25] without direct skin contact. The application of CBM is not limited to wearables, but also extends to furniture or fixtures such as beds [26,27], chairs [28,29], toilet seats [30], bathtubs [31], car seats [32,33], airplane seats [34], and operating tables [35]. However, compared to conventional biopotential measurement, which is based on resistive coupling, CBM requires an analog front end (AFE) with ever-higher input impedance in the measuring system so as not to cause voltage loss in the capacitive coupling of each measuring site. Meanwhile, as the time constant of the measuring system is a product of the input impedance and coupling capacitance of the measuring site, the more the input impedance of AFE increases, the longer the time constant becomes. Consequently, ever-higher input impedance, which is necessary for sensitive CBM, prolongs the baseline recovery (BR) time. BR time is a period when measurement is not possible due to out-of-range voltage input, which is caused mostly by triboelectricity [36] and/or static electricity. Out-of-range input commonly develops in CBM due to the body movements of the user but also the movements of others around the user, particularly under low-humidity conditions. The involvement of chemical textiles and thick clothing (or insulator) as an interfacing material between the skin and electrode also causes the out-of-range input. Therefore, finding a compromise between sensitivity (i.e., ever-higher input impedance) and stability (i.e., lower input impedance resulting in a shorter time constant) is an important challenge to be addressed in AFE design to reinforce the practicality and versatility of CBM, as noted in the literature [37].

Another issue related to the ever-higher input impedance of AFE is an increased susceptibility to stray interference such as power-line noise and its harmonics. In many cases, the housing and lead wires around AFE adopt a driven shield for interference suppression. A double shield, which is a combination of the driven shield and ground shield, was applied to multi-layered fabric electrodes and was found to mitigate motion-induced artifacts as well as the stray interference [38]. Furthermore, active ground is well known to be highly effective in reducing power-line noise [28]. Nevertheless, technical demand for noise suppression is still a matter of concern in CBM. This is because CBM is expected to be used in much noisier settings. Based on these considerations, we proposed a novel AFE that can cope with the need to find a balance between sensitivity and stability in CBM, which can also contribute to noise reduction. The proposed AFE was validated by measuring capacitive ECG (cECG) and capacitive EMG (cEMG) in low-humidity conditions. The signals of the cECG and cEMG that were obtained using the proposed AFE were compared with those obtained using a AFE that had been used in previous studies [27,39-42].

\section{Previous and Proposed Analog Front End}

A bootstrapped voltage follower with capacitance feedback $\left(\mathrm{BVF}_{c f}\right)$, which is shown in Figure 1a, was employed as an AFE in CBM in several previous studies [27,40-42]. This BVF $_{c f}$ was first proposed by Thakor et al. in 1980 for conventional ECG measurements [39]. Its complex input impedance $\dot{Z}_{\text {in_BVF }}$ is expressed in Equation (1), which assumes that the characteristics of the operational amplifier (OP Amp) used in the circuit are ideal [43].

$$
\dot{Z}_{i n \_B V F}(f)=\left(R_{a 1}+R_{a 2}\right)+j 2 \pi f C_{a 3} R_{a 1} R_{a 2}
$$


where $R_{a 1}, R_{a 2}$ are resistance, and $C_{a 3}$ is the capacitance for feedback in Figure $1 \mathrm{a}$, and $f$ is frequency. According to Equation (1), the magnitude of $\dot{Z}_{i n \_B V F}$ varies with the frequency component in the input signal (i.e., it is frequency-dependent) and can be approximated into two states using corner frequency $f_{c a}=\left(R_{a 1}+R_{a 2}\right) /\left(2 \pi C_{a 3} R_{a 1} R_{a 2}\right)$, as shown in Equation (2):

$$
\left|\dot{Z}_{i n \_B V F}(f)\right|=\sqrt{\left(R_{a 1}+R_{a 2}\right)^{2}+\left(2 \pi f C_{a 3} R_{a 1} R_{a 2}\right)^{2}} \cong\left\{\begin{aligned}
R_{a 1}+R_{a 2}, & f \ll f_{c a} \\
\left(2 \pi C_{a 3} R_{a 1} R_{a 2}\right) f, & f \gg f_{c a}
\end{aligned}\right.
$$

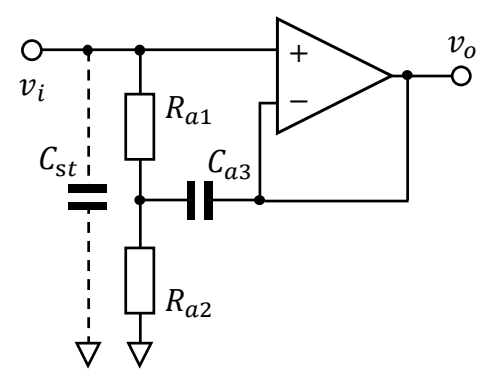

(a) Previous AFE $\left(\mathrm{BVF}_{c f}\right)$

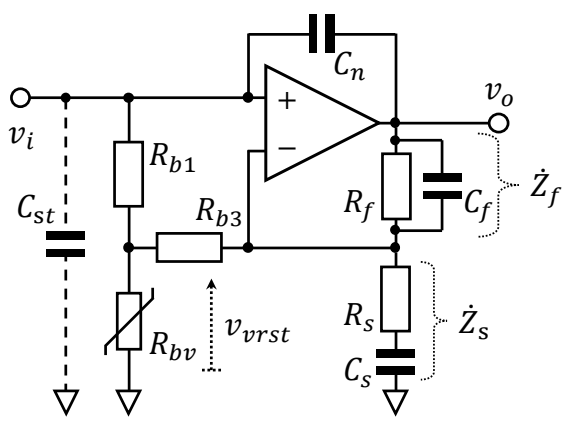

(b) Proposed AFE $\left(\mathrm{BNA}_{r f}\right)$

Figure 1. Configuration of analogue front ends (AFEs) involving bootstrapping techniques: (a) Previous AFE $\left(\mathrm{BVF}_{c f}\right)$ bootstrapped by resistors $R_{a 1}$ and $R_{a 2}$, and a feedback capacitor $C_{a 3}$. This serves as a voltage follower; (b) Proposed AFE (BNA $\mathrm{B}_{r f}$ ) bootstrapped by resistors $R_{b 1}$ and $R_{b 3}$, and a varistor with voltage-dependent resistance $R_{b v}$. This serves as a non-inverting bandpass amplifier by the use of resistors $R_{\mathrm{S}}$ and $R_{f}$, and capacitors $C_{s}$ and $C_{f}$. A capacitor $C_{n}$ is incorporated to reduce stray capacitance $C_{s t}$.

For an input frequency much lower than $f_{c a}$ (e.g., the direct-current (DC) component), $\left|\dot{Z}_{\text {in_BVF }}\right|$ is simply $\left(R_{a 1}+R_{a 2}\right)$ and contributes to shortening the BR time as reported in [41]. With a sufficiently higher frequency component than $f_{c a},\left|\dot{Z}_{i n_{-} B V F}\right|$ becomes ever-higher to enable CBM by the use of large $C_{a 3}$. However, positive proportionality to frequency in $\dot{Z}_{i n \_B V F}$ is equivalent to inductive characteristics. Therefore, the use of $\mathrm{BVF}_{c f}$ in $\mathrm{CBM}$, combined with capacitance of the skin-electrode coupling can cause resonant ringing in the signal and lead to signal instability [43].

The proposed novel AFE shown in Figure $1 \mathrm{~b}$ is a bootstrapped non-inverting amplifier with resistance feedback $\left(\mathrm{BNA}_{r f}\right)$, which has three features: (F-1) voltage-dependent input impedance, (F-2) bandpass amplification, and (F-3) stray capacitance reduction. The first feature (F-1) is attained by a bootstrapping part composed of a resistor $R_{b 1}$, a varistor with voltage-dependent resistance $R_{b v}$ and a feedback resistor $R_{b 3}$ as shown in Figure 1b. Given the varistor has a non-linear resistance that varies with the applied voltage $\boldsymbol{v}_{\text {vrst }}$ relative to threshold voltages $\pm V_{t h r}$ as follows:

$$
R_{b v} \approx\left\{\begin{aligned}
R_{h}, & \text { if }-V_{\text {thr }}<v_{\text {vrst }}<+V_{\text {thr }} \\
0, & \text { else }
\end{aligned}\right.
$$

Then the input impedance of $\mathrm{BNA}_{r f}, Z_{\text {in_BNA}}$, also becomes non-linear and varies with the input voltage $v_{i}$ (i.e., it is voltage-dependent). By applying star-delta transformation to the bootstrapping part in Figure 1b, combining virtual short concept of ideal OP Amp, and substituting Equation (3) into the derived input impedance, we can obtain the following:

$$
Z_{\text {in_BNA }}=R_{b 1}+R_{b v}+\frac{R_{b 1} R_{b v}}{R_{b 3}} \approx\left\{\begin{array}{cl}
\frac{R_{b 1}}{R_{b 3}} R_{h}, & \text { if }-V_{t h r}<\frac{R_{h}}{R_{h}+R_{b 3}} v_{i}<+V_{t h r} \\
R_{b 1}, & \text { else }
\end{array}\right.
$$


According to Equation (4), when $v_{i}$ is within a range between $\pm V_{t h r}\left(1+R_{b 3} / R_{h}\right), Z_{\text {in_BNA }}$ can be ever-higher enough for sensitive CBM by choosing a low resistance for $R_{b 3}$, a medium (or high) resistance for $R_{b 1}$, and a high resistance for $R_{h}$. Since normal $v_{i}$ (i.e., the biopotential at each measuring site) is in the order of millivolts at most, $v_{i}$ falls within the range between $\pm V_{t h r}\left(1+R_{b 3} / R_{h}\right)$ by choosing a varistor with $V_{t h r}$ in the order of volts. On the other hand, for $v_{i}$ outside the range, $Z_{\text {in_BNA }}$ becomes simply $R_{b 1}$ (i.e., medium) and contributes to shortening the BR time (i.e., stability in CBM). So, that means that the voltage-dependent input impedance of the proposed $\mathrm{BNA}_{r f}$ in Equation (4) can achieve a feasible balance between sensitivity and stability in the CBM. Furthermore, when the range between $\pm V_{t h r}\left(1+R_{b 3} / R_{h}\right)$ is narrower than that between power-supply voltages to the OP Amp, $\pm V_{C C}$, the bootstrapping part that includes the varistor also works as pre-over-voltage protection for the subsequent OP Amp, leading to increased durability of the proposed AFE.

The second feature (F-2) of the proposed BNA $\mathrm{Br}_{r f}$ (i.e., bandpass amplification) is attained, as shown in Figure $1 \mathrm{~b}$ by the combination of a parallel connection of $R_{f}$ and $C_{f}$, and a series connection of $R_{S}$ and $C_{s}$. With the use of complex impedances of these connections, $\dot{Z}_{f}$ and $\dot{Z}_{s}$, complex voltage gain $\dot{A}_{v}$ of the non-inverting amplifier can be expressed, as shown in Equation (5):

$$
\dot{A}_{v}(f)=1+\frac{\dot{Z}_{f}}{\dot{Z}_{s}}=1+\frac{R_{f}}{R_{s}} \cdot \frac{1}{\left(1+j 2 \pi f C_{f} R_{f}\right)} \cdot \frac{j 2 \pi f C_{s} R_{s}}{\left(j 2 \pi f C_{s} R_{s}+1\right)}
$$

For Equation (5), we can define corner frequencies of $f_{c f}=1 /\left(2 \pi C_{f} R_{f}\right)$ and $f_{c s}=1 /\left(2 \pi C_{s} R_{s}\right)$, for $\dot{Z}_{f}$ and $\dot{Z}_{s}$, respectively. When we set the frequency band $\left(f_{c f}-f_{c s}\right)$ wide enough, $\dot{A}_{v}$ is approximated into two transition frequency regions and an in-between passband region, as follows:

$$
\dot{A}_{v}(f) \approx\left\{\begin{aligned}
1+\frac{R_{f}}{R_{s}} \cdot \frac{j\left(f / f_{c s}\right)}{j\left(f / f_{c s}\right)+1}, & f<f_{c S} \ll f_{c f} \\
1+\frac{R_{f}}{R_{s}}, & f_{c S} \ll f \ll f_{c f} \\
1+\frac{R_{f}}{R_{s}} \cdot \frac{1}{1+j\left(\frac{f}{f_{c f}}\right)}, & f_{c s} \ll f_{c f}<f
\end{aligned}\right.
$$

For a frequency $f$ between $f_{c s}$ and $f_{c f}$ in Equation (6), the amplification factor of $\mathrm{BNA}_{r f}$ is a constant $\left(1+R_{f} / R_{s}\right)$. Thus, we can consider $\mathrm{BNA}_{r f}$ as a non-inverting amplifier for the frequency band of concern. Meanwhile, for the lower or higher frequency region of the relevant band, the amplitude of $\mathrm{BNA}_{r f}$ gradually changes from $\left(1+R_{f} / R_{s}\right)$ to 1 as frequency $f\left(<f_{c s}\right)$ decreases or frequency $f$ $\left(>f_{c f}\right)$ increases, respectively. Therefore, $\mathrm{BNA}_{r f}$ behaves as a bandpass amplifier. In general, frequency confinement in amplification increases a percentage of the desired signal with the target frequencies in the output. Since an AFE with ever-higher input impedance is susceptible to surrounding noise, this feature (i.e., bandpass amplification) of $\mathrm{BNA}_{r f}$ contributes to improvement in the signal-to-noise ratio (SNR) in CBM signals.

The third feature (F-3) of the proposed $\mathrm{BNA}_{r f}$, (i.e., stray capacitance reduction) is only attained by inserting a capacitor $C_{n}$ as indicated in Figure $1 \mathrm{~b}$ [44]. While stray capacitance $C_{s t}$ in Figure $1 \mathrm{~b}$ inevitably incurs leak current $\dot{I}_{l k}$ depending on the potential difference between the non-inverting input node $\left(\dot{V}_{i}\right)$ and ground (0) of the OP Amp, the inserted $C_{n}$ yields compensating current $\dot{I}_{c p}$ depending on the potential difference between the output node $\left(\dot{V}_{o}\right)$ and the non-inverting input node $\left(\dot{V}_{i}\right)$. As each current is obtained from the potential difference divided by impedance of the capacitance and the gain of the amplifier is given by Equation (6), remaining leak current $\ddot{I}_{l k}^{\prime}$ for the concerned frequencies $f$ (i.e., $\left.f_{c s} \ll f \ll f_{c f}\right)$ is expressed as follows:

$$
\ddot{I}_{l k}^{\prime}=\dot{I}_{l k}-\dot{I}_{c p}=j 2 \pi f C_{s t}\left(\dot{V}_{i}-0\right)-j 2 \pi f C_{n}\left(\dot{V}_{o}-\dot{V}_{i}\right)=j 2 \pi f\left(C_{s t}-\frac{R_{f}}{R_{s}} C_{n}\right) \dot{V}_{i}
$$


According to Equation (7), we can consider the inserted $C_{n}$ to be negative capacitance $-\left(R_{f} / R_{s}\right) C_{n}$, reducing stray capacitance $C_{s t}$. Since $\dot{I}_{c p}$ corresponds to positive feedback current, it should be smaller than $\dot{I}_{l k}$ (i.e., $\dot{I}_{l k}^{\prime}>0$ ) for the prevention of oscillation. Therefore, $C_{n}$ has to be set to satisfy Equation (8):

$$
C_{n}<\frac{R_{s}}{R_{f}} C_{s t}
$$

\section{Experimental and Analytical Methods}

All experimental procedures were approved by the Human Life Ethics Committee of Tokyo Denki University. All subjects provided informed consent prior to participation in our experiments.

\subsection{Implementation of Previous and Proposed AFEs for Evaluation}

To evaluate the proposed AFE (BNA $\left.{ }_{r f}\right), c E C G$ and $c E M G$ were measured using $\mathrm{BNA}_{r f}$ and using a previous $\mathrm{AFE}\left(\mathrm{BVF}_{c f}\right)$ as a reference. Both $\mathrm{AFEs}$ were prototyped using off-the-shelf components. The same type of OP Amp with high input impedance (Texas Instruments, OPA129, 10T $\Omega / / 1 \mathrm{pF}$ according to the specification sheet) was employed to prevent degrading the input impedance synthesized in parallel with the bootstrapping part. The values of the elements used for circuit implementation and their specifications are shown in Table 1. Corner frequencies for bandpass in $\mathrm{BNA}_{r f}$ (i.e., $f_{c s}$ and $f_{c f}$ ) were separately designed and implemented for CECG and CEMG, as can be seen in the frequency-gain characteristics shown in Figure 2. We confirmed that the measured characteristics in Figure 2 agreed with the theoretical characteristics described in Equation (6), and that $f_{c s}$ and $f_{c f}$ can be designed independently in conjunction with the gain for the concerned frequency $f\left(f_{c s} \ll f \ll f_{c f}\right)$.

Table 1. Specifications and values of the elements used in the implementation of the previous and proposed AFEs for capacitive electrocardiogram (cECG) and capacitive electromyogram (cEMG) measurements.

\begin{tabular}{|c|c|c|c|c|c|c|}
\hline Item & \multicolumn{3}{|c|}{ Previous AFE $\left(\mathrm{BVF}_{c f}\right)$} & \multicolumn{3}{|c|}{ Proposed AFE $\left(\mathrm{BNA}_{r f}\right)$} \\
\hline Gain & $\begin{array}{l}\text { Total } \\
60 \mathrm{~dB}\end{array}$ & $\begin{array}{l}\text { AFE } \\
0 \mathrm{~dB}\end{array}$ & $\begin{array}{l}\text { Subsequent } \\
\quad 60 \mathrm{~dB}\end{array}$ & $\begin{array}{l}\text { Total } \\
60 \mathrm{~dB}\end{array}$ & $\begin{array}{c}\operatorname{AFE}\left(R_{s}, R_{f}\right) \\
20 \mathrm{~dB} \\
(30 \mathrm{k}, 270 \mathrm{k} \Omega)\end{array}$ & $\begin{array}{c}\text { Subsequent } \\
\quad 40 \mathrm{~dB}\end{array}$ \\
\hline Bootstrap & $\begin{array}{c}R_{a 1} \\
100 \mathrm{M} \Omega\end{array}$ & $\begin{array}{c}R_{a 2} \\
100 \mathrm{M} \Omega\end{array}$ & $\begin{array}{c}C_{a 3} \\
100 \mu \mathrm{F}\end{array}$ & $\begin{array}{c}R_{b 1} \\
100 \mathrm{M} \Omega\end{array}$ & $\begin{array}{c}R_{b v} \\
20 \mathrm{M} \Omega / 0 \Omega\end{array}$ & $\begin{array}{c}R_{b 3} \\
1.0 \mathrm{k} \Omega\end{array}$ \\
\hline Bandpass & & NA & & $\begin{array}{c}\text { Measurand } \\
\text { cECG } \\
\text { cEMG }\end{array}$ & $\begin{array}{c}f_{C S}\left(C_{s} \mu \mathrm{F}\right) \\
0.50 \mathrm{~Hz}(10.7) \\
20.0 \mathrm{~Hz}(2.67)\end{array}$ & $\begin{array}{c}f_{c f}\left(C_{f} \mathrm{nF}\right) \\
103 \mathrm{~Hz}(5.70) \\
513 \mathrm{~Hz}(1.15)\end{array}$ \\
\hline Stray Cap. Reduction & & NA & & & $\begin{array}{c}C_{n} \\
1.0 \mathrm{pF}\end{array}$ & \\
\hline
\end{tabular}

NA: not applicable, Cap.: Capacitance.

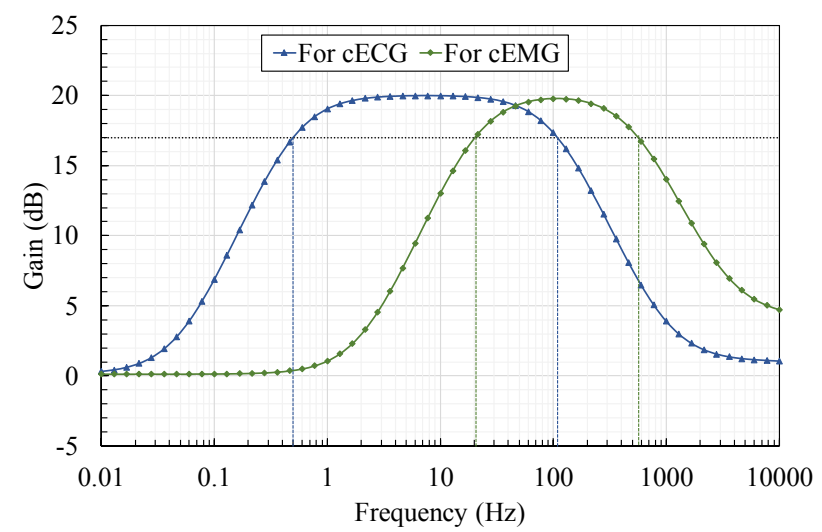

Figure 2. Frequency-gain characteristics of the proposed AFE with bandpass amplification tuned separately for CECG and cEMG measurements. Maximum gains were set to $20 \mathrm{~dB}$ for both measurements. Frequency passbands were set to $0.5-103 \mathrm{~Hz}$ for cECG and to 20-513 Hz for cEMG, respectively. 


\subsection{Measurements of cECG through Thick Clothing in a Low-Humidity Environment}

In order to verify compatibility between the sensitivity and stability of the proposed $\mathrm{BNA}_{r f}$ in $\mathrm{CBM}, \mathrm{cECG}$ signal was measured using $\mathrm{BNA}_{r f}$ under some challenging conditions for the measurement, where 1.70-mm thick clothing was placed between the skin and electrode, and the relative humidity was set to lower than $35 \%$. For the purpose of comparison, another $\mathrm{CECG}$ signal was measured using $\mathrm{BVF}_{c f}$ under the same conditions in a sequential manner. Four subjects with different body mass indexes (BMIs), falling within the range of healthy-weight (18.5-25) or overweight (25-30) BMI, participated in this experiment. Subject information and the measurement conditions are presented in Table 2. Since the BMI is defined as the body mass divided by the square of the body height and is universally expressed in units of $\mathrm{kg} / \mathrm{m}^{2}$, the BMI of the subject under the force of gravity correlates roughly with the pressure of the capacitive coupling between the subject's dorsal surface in a supine position and the electrode placed under the subject via the clothing. We selected these subjects to examine the effect of the coupling pressure on the quality of the obtained CECG signal. In the experiment, the subjects were requested to sit on a bed for $10 \mathrm{~s}$, change their posture to a supine position on cue, and remain lying supine on the bed for $12 \mathrm{~min}$ with a constant breathing rate at $0.25 \mathrm{~Hz}$ in tune with the sound from a metronome.

Table 2. Subject information and experimental conditions in cECG measurement.

\begin{tabular}{|c|c|c|c|c|c|c|c|c|}
\hline \multirow{2}{*}{ ID } & \multicolumn{4}{|c|}{ Subject Information } & \multirow{2}{*}{$\begin{array}{c}\text { Clothing } \\
\begin{array}{c}\text { Thickness } \\
(\mathrm{mm})\end{array}\end{array}$} & \multicolumn{3}{|c|}{ Experimental Conditions } \\
\hline & $\begin{array}{l}\text { Height } \\
\text { (m) }\end{array}$ & $\begin{array}{l}\text { Weight } \\
\text { (kg) }\end{array}$ & $\begin{array}{c}\text { BMI } \\
\left(\mathrm{kg} / \mathrm{m}^{2}\right)\end{array}$ & Age & & RH (\%) & $\begin{array}{c}\text { Temperature } \\
\left({ }^{\circ} \mathrm{C}\right)\end{array}$ & $\begin{array}{c}\mathrm{VH} \\
\left(\mathrm{g} / \mathrm{m}^{3}\right)\end{array}$ \\
\hline \#A & 1.65 & 60 & 22.0 & 22 & 1.70 & 22.0 & 24.0 & 4.79 \\
\hline \#B & 1.63 & 70 & 26.4 & 23 & 1.70 & 22.0 & 24.0 & 4.79 \\
\hline \#C & 1.61 & 74 & 28.6 & 23 & 1.70 & 32.6 & 25.0 & 7.52 \\
\hline \#D & 1.69 & 59 & 20.7 & 23 & 1.70 & 17.0 & 24.8 & 3.88 \\
\hline
\end{tabular}

BMI: body mass index, RH: relative humidity, VH: volumetric humidity.

As shown in Figure 3, a flexible sheet electrode (FSE), which was modified from previous studies $[27,45]$, was used for the cECG measurements. The FSE is constructed from thin, soft conductive fabric (CSTK, Kitagawa Industries) and insulating textiles (100\% polyester), and it has a total thickness of $0.45 \mathrm{~mm}$. The FSE was placed under bed sheets made from $0.31 \mathrm{~mm}$ cotton, and underneath the back of the lying subject. All subjects wore a commercially available sweatshirt (96\% cotton, $4 \%$ polyurethane) with a thickness of $0.84 \mathrm{~mm}$, and an undershirt ( $66 \%$ cotton, $34 \%$ polyester) with a thickness of $0.55 \mathrm{~mm}$. Therefore, the total thickness of the interface clothing between the skin and electrode was set to $1.70 \mathrm{~mm}$.

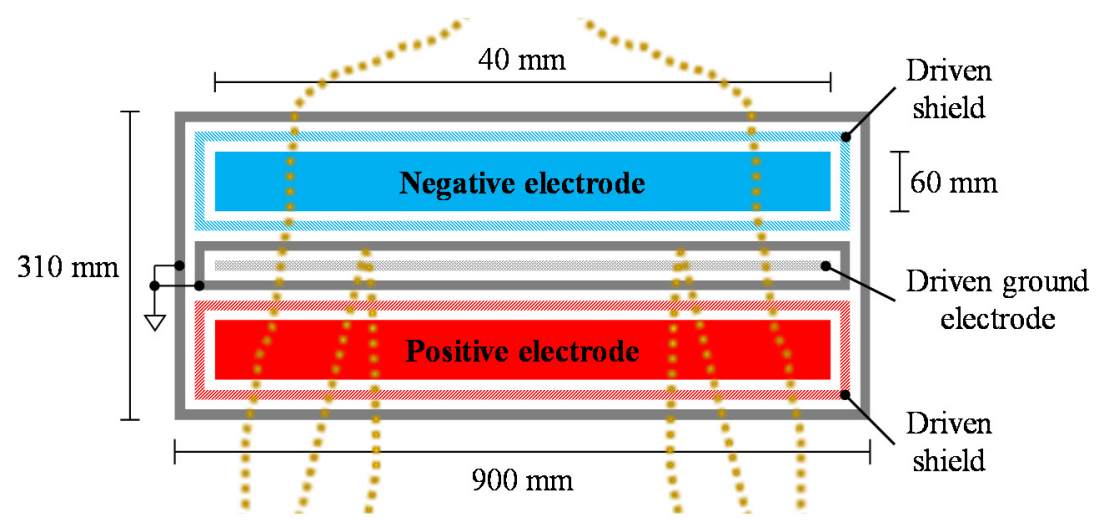

Figure 3. Top view configuration of flexible sheet electrode (FSE) for cECG measurement. The configuration was modified from $[27,45]$. 
The cECG signal was measured using the system shown in Figure 4. The reference Lead II ECG and respiratory movement (RM) signals were measured simultaneously with a commercially available telemetry system (BN-RSPEC, BIOPAC Systems). The frequency band of the circuits after the AFE was set to $0.5-100 \mathrm{~Hz}$. The gain in the circuits was set to $40 \mathrm{~dB}$ in the measurement using the proposed $\mathrm{BNA}_{r f}$, but to $60 \mathrm{~dB}$ in the measurement using $\mathrm{BVF}_{c f}$, so that the total gain of the measurement system including AFE became $60 \mathrm{~dB}$ in both measurements.

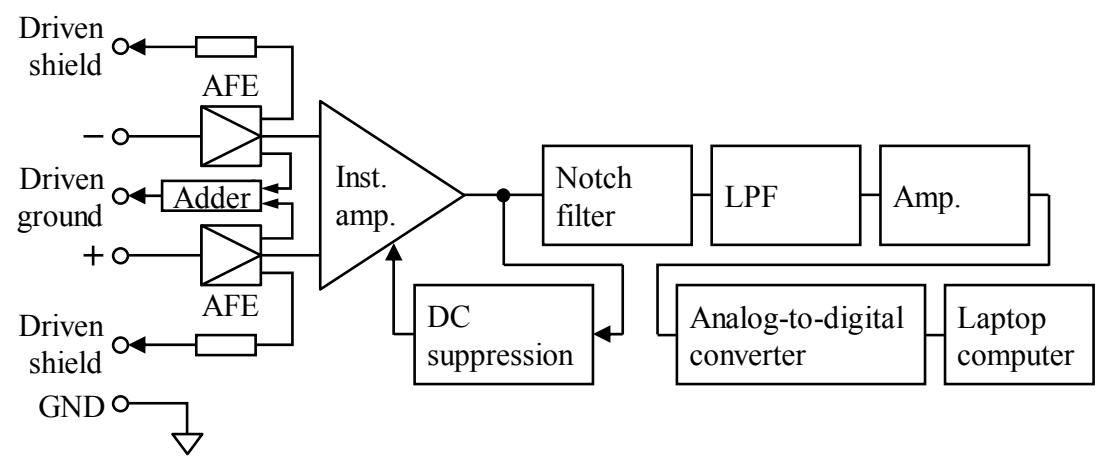

Figure 4. Schematic diagram of the measuring system for both cECG and cEMG. Total gain including AFE was set to $60 \mathrm{~dB}$ according to the type of AFE. The frequency bands achieved by a combination of DC suppression and low-pass filter (LPF) were set to $0.5-100 \mathrm{~Hz}$ for cECG measurement and to 20-500 Hz for cEMG measurement, respectively. The analog signal was digitized at $1000 \mathrm{~Hz}$ with 16-bit resolution between -10 and $+10 \mathrm{~V}$ by the analog-to-digital converter.

\subsection{Analysis of cECG Signals for Evaluation}

Measured voltage of cECG signals was converted to input-referred voltage as a preprocessing common to $\mathrm{BVF}_{c f}$ and $\mathrm{BNA}_{r f}$. As the first step to determine BR time for each cECG measurement, the baseline component was extracted from each cECG signal by applying a $0.15 \mathrm{~Hz}$ low-pass filter (LPF). Next, the steady-state baseline level (i.e., bias voltage) was computed as the mean of the baseline component from $60 \mathrm{~s}$ to $80 \mathrm{~s}$ after the onset of lying down on the bed. Finally, BR time was determined as the time required for the baseline component to return to a range of $\pm 0.5 \mathrm{mV}$ of the steady-state baseline level and to stay within the range for more than $10 \mathrm{~s}$. A shorter BR time reflects the higher stability of the AFE used in the measurement against out-of-range input.

In order to evaluate the insusceptibility of the used AFE to RM disturbance in cECG measurement, the RM component around $0.25 \mathrm{~Hz}$ was extracted from each cECG signal by applying a $0.15-0.5 \mathrm{~Hz}$ bandpass filter. For each time-series RM component, the root mean square voltage $\left(\mathrm{RMSV}_{\text {resp }}\right)$ was calculated by the minute from the onset of lying down on the bed. A smaller RMSV $\mathrm{V}_{\text {resp }}$ means the used AFE has higher insusceptibility to RM disturbance.

\subsection{Measurements of cEMG in a Low-Humidity Environment}

In order to compare the performance of the previous and proposed AFEs in terms of SNR, the cEMG signal was measured in a sequential manner using either AFE where the relative humidity was lower than $35 \%$. Low-humidity conditions are known to easily cause low-SNR output in CBM. The cEMG measurement was also executed to confirm the versatility of the proposed AFE. Three male subjects participated to this experiment. Subject information and the measurement conditions are summarized in Table 3. Each subject wore a commercially available long-sleeve cotton shirt, which was $0.26 \mathrm{~mm}$ thick. A flexible pad electrode shown in Figure 5 was fixed on the right biceps brachii muscle over the shirt by using a bandage. An additional driven ground electrode (DGE) was fixed near the right elbow, also over the shirt. The pad electrode was constructed from the same materials as the sheet electrode for the CECG measurements. The configuration of the pad electrode was modified based on studies in the literature $[21,42,45]$. 
Table 3. Subject information and experimental conditions in cEMG measurement.

\begin{tabular}{ccccccccc}
\hline \multirow{2}{*}{ ID } & \multicolumn{3}{c}{ Subject Information } & \multicolumn{2}{c}{ Clothing } & \multicolumn{2}{c}{ Experimental Conditions } \\
\cline { 2 - 8 } & $\begin{array}{c}\text { Height } \\
(\mathbf{m})\end{array}$ & $\begin{array}{c}\text { Weight } \\
\mathbf{( k g )}\end{array}$ & $\begin{array}{c}\text { BMI } \\
\mathbf{( k g / \mathbf { m } ^ { \mathbf { 2 } } )}\end{array}$ & Age & $\begin{array}{c}\text { Thickness } \\
(\mathbf{m m})\end{array}$ & RH (\%) & $\begin{array}{c}\text { Temperature } \\
\left({ }^{\circ} \mathbf{C}\right)\end{array}$ & $\begin{array}{c}\text { VH } \\
\left(\mathbf{g} / \mathbf{m}^{\mathbf{3}}\right)\end{array}$ \\
\hline \#E & 1.71 & 56 & 19.2 & 24 & 0.26 & 19.0 & 23.0 & 3.91 \\
\#F & 1.80 & 92 & 28.4 & 23 & 0.26 & 19.0 & 23.0 & 3.91 \\
\#G & 1.70 & 73 & 25.3 & 23 & 0.26 & 33.0 & 23.2 & 6.87 \\
\hline
\end{tabular}
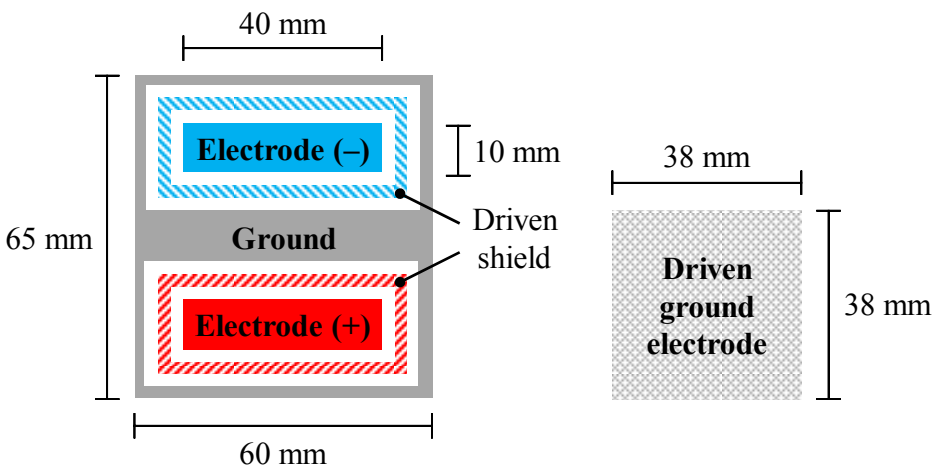

Figure 5. Top view configuration of flexible pad electrode (left) and driven ground electrode (DGE, right) employed for cEMG measurement. The pad electrode has a five-layered structure. DGE is used for the negative feedback of a voltage synthesized from two voltages that were independently obtained with negative and positive electrodes in the pad.

In this experiment, each subject was requested to remain sitting in a chair and hold a $3 \mathrm{~kg}$ dumbbell in his right hand for $110 \mathrm{~s}$ with his right upper arm straight down at his side. While holding the dumbbell, the subject was instructed to bend his right elbow about 90 degrees with his upper arm straight down at his side, maintain the position for $10 \mathrm{~s}$, and straighten the elbow again. This instruction was provided three times at $30 \mathrm{~s}, 50 \mathrm{~s}$ and $70 \mathrm{~s}$ in the $110 \mathrm{~s}$ experiment. This experiment was repeated twice for each subject, one using the previous AFE and the other using the proposed AFE.

During the experiment, cEMG signal was measured using the system shown in Figure 4. The frequency band of the circuit after the AFE was set to 20-500 Hz by combining the DC suppression circuit and LPF, as shown in the figure. The gain of the circuit after the AFE was adjusted so that the total gain of the measuring system became $60 \mathrm{~dB}$, irrespective of AFE type. The reference EMG $\left(\mathrm{EMG}_{\mathrm{ref}}\right)$ signal was simultaneously measured with a commercially available EMG amplifier (BA1104M, TEAC Instruments), telemetry system (TU-4, TEAC Instruments), and disposable electrodes (F-150S, Nihon Kohden). The disposable electrodes were directly attached on the skin near the right biceps brachii muscle so that they did not interfere with the pad electrode for cEMG measurement.

\subsection{Analysis of cEMG Signals for Evaluation}

The measured voltage of $c E M G$ and $E M G_{\text {ref }}$ signals was converted to input-referred voltage as a preprocessing similar to that described in 3.3. For cEMG signals, the 10 s period of "elbow bended" and the subsequent $10 \mathrm{~s}$ period of "elbow straightened" were considered as a pair, and two segments of 4000 samples, from $4 \mathrm{~s}$ to $8 \mathrm{~s}\left(v_{i}{ }^{(S+N)}\right)$ and from $14 \mathrm{~s}$ to $18 \mathrm{~s}\left(v_{i}{ }^{(N)}\right)$ were extracted from the one pair. A total of twelve segments were extracted from one subject; 6 (i.e., 3 pairs) from signals measured with the previous AFE, and the other 6 from signals measured with the proposed AFE. To compare the 
signal quality of cEMG of the two AFEs, digital Fourier transform (DFT) was applied to each segment. In addition, SNR was computed from each pair of the two segments as follows:

$$
\begin{gathered}
\operatorname{SNR}(v)=20 \log _{10} \frac{\sqrt{\frac{1}{n} \sum_{i=1}^{n}\left(v_{i}(S+N)-v_{i}^{(N)}-V_{\text {Bias }}(S)\right)^{2}}}{\sqrt{\frac{1}{n} \sum_{i=1}^{n}\left(v_{i}^{(N)}-V_{\text {Bias }}(N)\right)^{2}}}(\mathrm{~dB}) \\
V_{\text {Bias }}{ }^{(S)}=\frac{1}{n} \sum_{i=1}^{n}\left(v_{i}^{(S+N)}-v_{i}^{(N)}\right) \\
V_{\text {Bias }}{ }^{(N)}=\frac{1}{n} \sum_{i=1}^{n} v_{i}^{(N)}
\end{gathered}
$$

We considered that the "elbow bended" segments contain both myoelectric signal and noise $(S+N)$, while "elbow straightened" segments include noise only $(N)$.

\section{Results}

\section{1. cECG Measurements through Thick Clothing in a Low-Humidity Environment}

Figure 6 shows the contrast in the transitions of cECG signals measured with either the previous or the proposed AFEs for two subjects \#A and \#C with different BMIs. In spite of a challenging environment for the measurement, both systems were able to detect visible cECG waveforms from all subjects by the end of the $12 \mathrm{~min}$ measurement period. For the subjects within a healthy-weight $\mathrm{BMI}$ range (i.e., \#A, \#D), however, the systems showed a big difference in the stability of the signal baseline, as can be seen in Figure $6 a, b$. The baseline of the cECG signal obtained with the previous AFE (Figure 6a) fluctuated, even at the end of the measurement, whereas that obtained with the proposed AFE (Figure $6 \mathrm{~b}$ ) fluctuated moderately. Consequently, $\mathrm{T}$ waves as well as $\mathrm{R}$ waves became visible toward the end of the measurement period, as can be seen in Figure $6 \mathrm{~b}$. The fluctuations of both seemed to be cyclic with a period of around $4 \mathrm{~s}$, inferring an association with the $0.25-\mathrm{Hz}$ breathing.
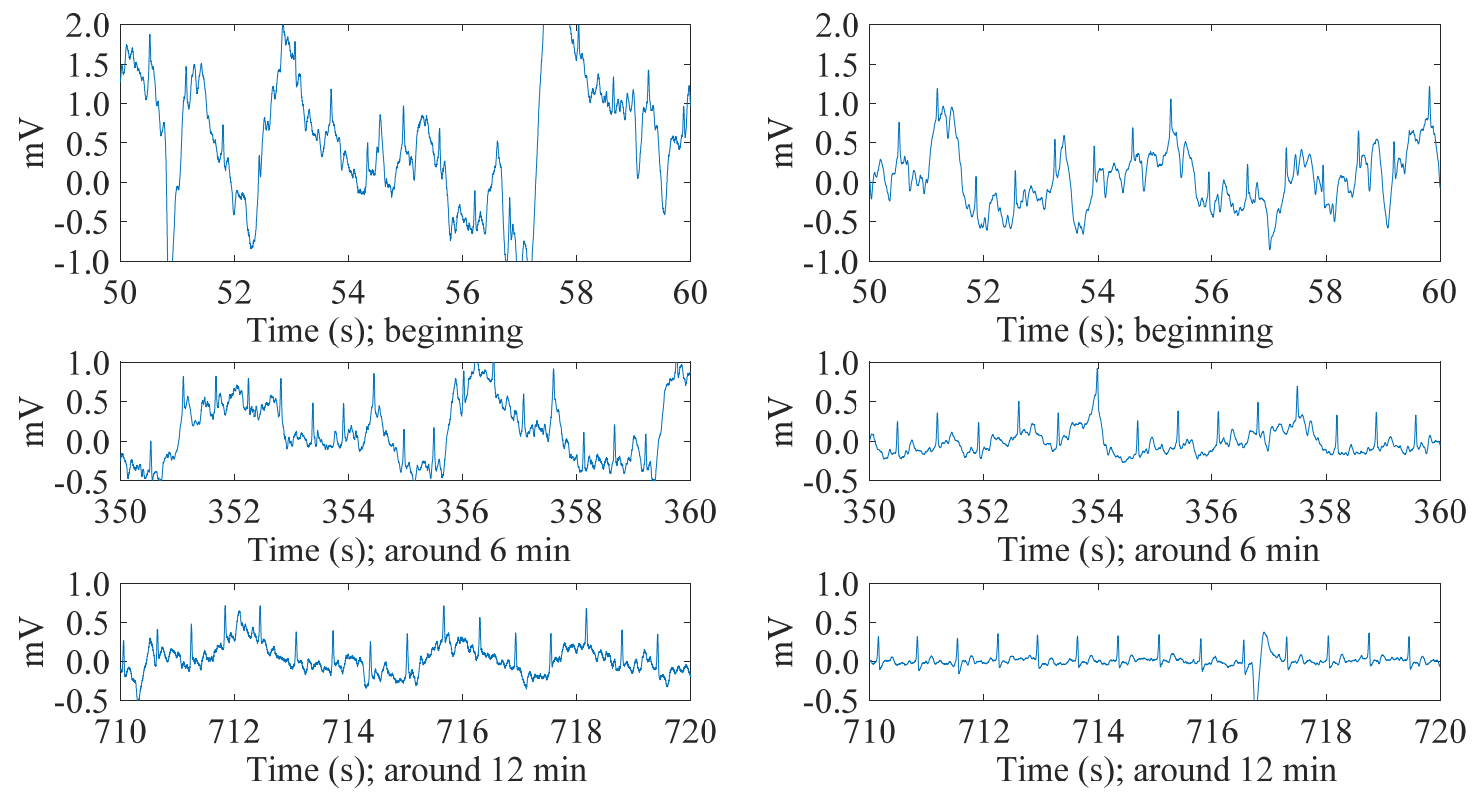

(a) Previous AFE (subject \#A, BMI 22.0)

(b) Proposed AFE (subject \#A, BMI 22.0)

Figure 6. Cont. 

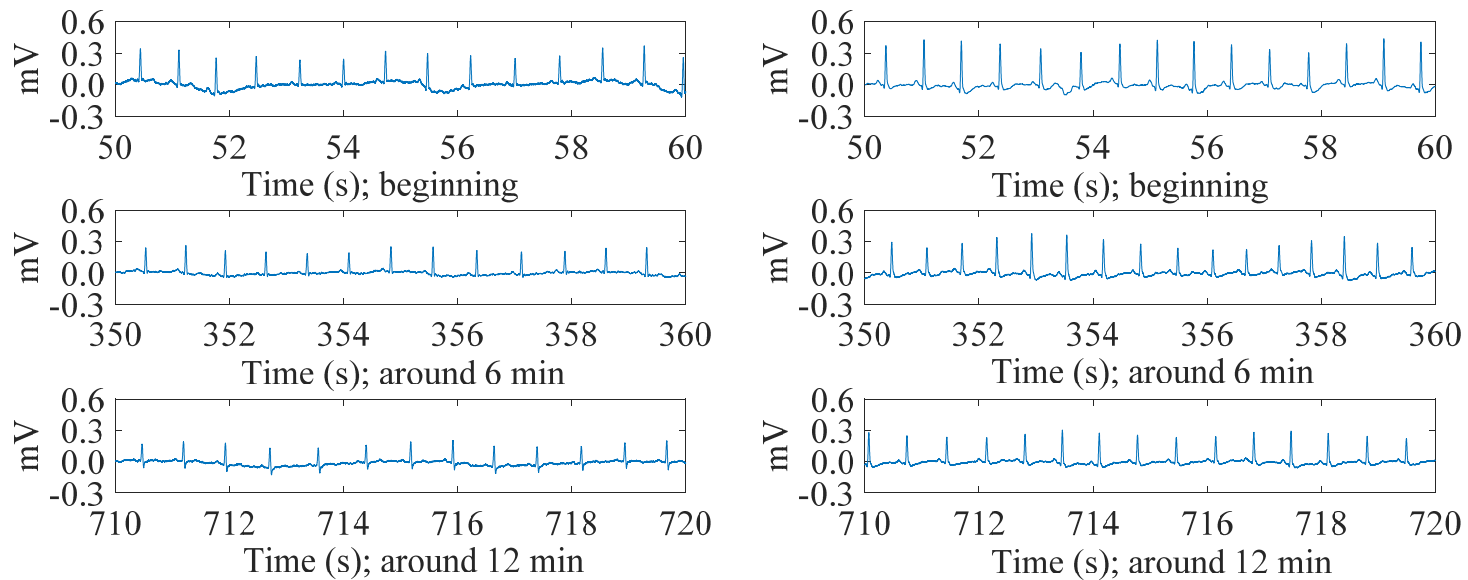

(c) Previous AFE (subject \#C, BMI 28.6)

(d) Proposed AFE (subject \#C, BMI 28.6)

Figure 6. The transition of cECG recordings measured through thick clothing $(1.70 \mathrm{~mm})$ in low-humidity environments. The previous AFE was used for the recordings of $(\mathbf{a}, \mathbf{c})$, whereas the proposed AFE was used for the recordings of $(\mathbf{b}, \mathbf{d})$. Both recordings $(\mathbf{a}, \mathbf{b})$ were measured from a healthy-weight-BMI subject $(22.0, \# A)$, and recordings (c,d) were from an overweight-BMI subject $(28.6, \# C)$.

Meanwhile, for the subjects in the overweight BMI range (i.e., \#B, \#C), there was little difference in the baseline stability of the systems, as shown in Figure $6 \mathrm{c}, \mathrm{d}$. Using either the previous or proposed AFEs, the baseline of the cECG signal was stable from the beginning in each recording. In terms of the $\mathrm{R}$ wave amplitude, the system with the proposed AFE detected larger amplitude and was slight superior because of its higher input impedance.

\subsection{Evaluation of cECG Signals}

Figure 7 shows examples of the transient responses of the baseline to the onset of subject (\#A) with healthy-weight BMI lying down. With the use of the proposed AFE, the BR time decreased from $42.4 \mathrm{~s}$ to $8.9 \mathrm{~s}$. As in the case of the contrasting baseline responses in Figure 6, the BR times in Table 4 were significantly different for subjects \#A and \#D, who are within a healthy-weight BMI range. However, for subjects \#B and \#C who are in the overweight BMI range, the BR time showed little difference. For all subjects, the BR times with the proposed AFE were shorter than $10 \mathrm{~s}$.

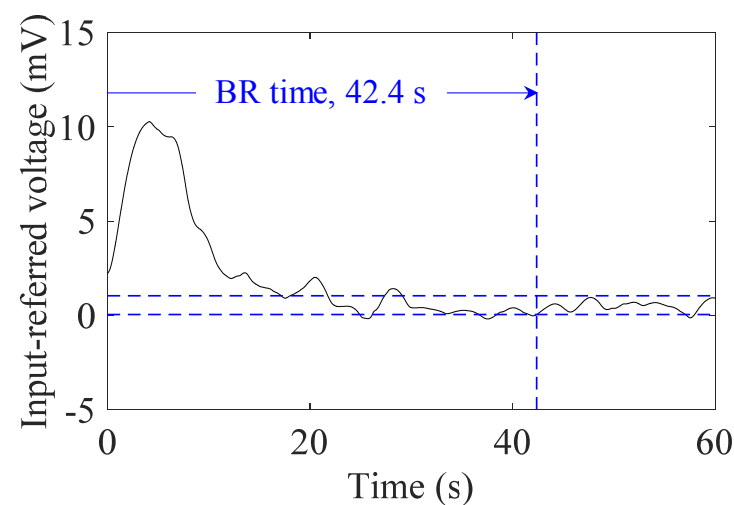

(a) Previous AFE

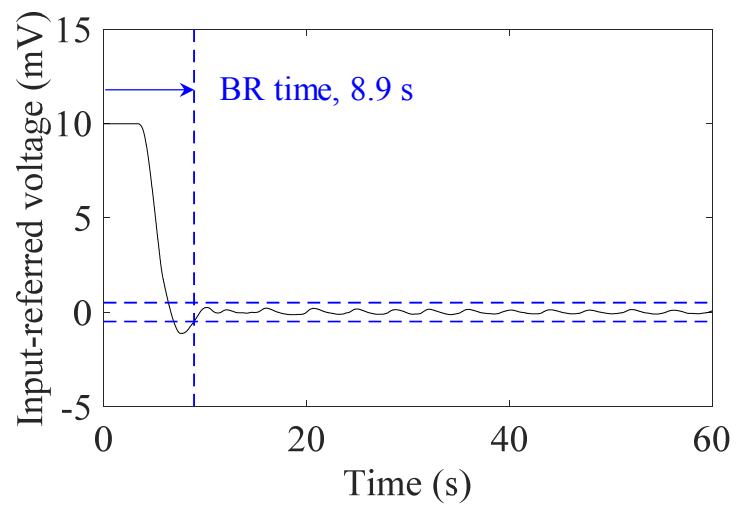

(b) Proposed AFE

Figure 7. Examples of transient response of cECG baseline to the onset of supine position of subject \#A. Original cECG signals were measured using the (a) previous AFE and (b) proposed AFE, and then filtered to extract their baselines, respectively. The baseline recovery (BR) time is also indicated in each response. 
Table 4. Comparison of BR time(s) between the previous and proposed AFEs. The BMI of each subject and the humidity during each measurement are also indicated.

\begin{tabular}{|c|c|c|c|c|c|}
\hline \multirow{2}{*}{ Subject ID } & \multicolumn{2}{|c|}{ BR Time (s) } & \multirow{2}{*}{ BMI $\left(\mathrm{kg} / \mathrm{m}^{2}\right)$} & \multicolumn{2}{|c|}{ Humidity } \\
\hline & Previous & Proposed & & RH (\%) & VH $\left(\mathrm{g} / \mathrm{m}^{3}\right)$ \\
\hline \#A & 42.4 & 8.9 & 22.0 & 22.0 & 4.79 \\
\hline \#B & 4.2 & 5.1 & 26.4 & 22.0 & 4.79 \\
\hline \#C & 6.6 & 6.4 & 28.6 & 32.6 & 7.52 \\
\hline \#D & 69.2 & 8.0 & 20.7 & 17.0 & 3.88 \\
\hline Mean \pm SD & $30.6 \pm 26.9$ & $7.1 \pm 1.5$ & $24.4 \pm 3.7$ & $23.4 \pm 5.7$ & $5.25 \pm 1.37$ \\
\hline
\end{tabular}

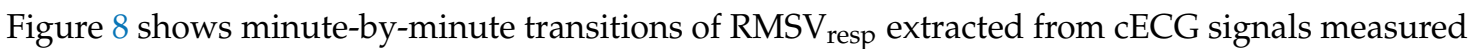
with the previous or proposed AFE for all four subjects. Comparing the transitions between the subjects irrespective of AFE type, transitions in the subjects within the overweight BMI range (\#B, \#C) dropped rapidly after $1 \mathrm{~min}$ as in Figure $8 \mathrm{~b}, \mathrm{c}$. On the other hand, for the subjects within the healthy-weight BMI range, transitions decreased gradually with time as can be seen in Figure 8a,d. These figures, show that compared with the previous AFE, the $\mathrm{RMSV}_{\text {resp }}$ obtained with the proposed AFE in every one minute was smaller in most times. Having grouped minute-by-minute twelve $\mathrm{RMSV}_{\text {resp }}$ data for each subject

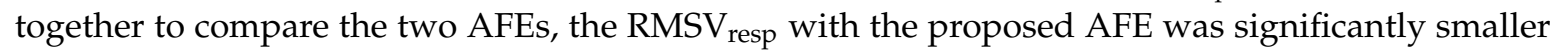
$(p<0.01)$ than that with the previous AFE for both subjects \#A and \#D (data not shown). These results were consistent with the results in Figures 6 and 7 and Table 4.

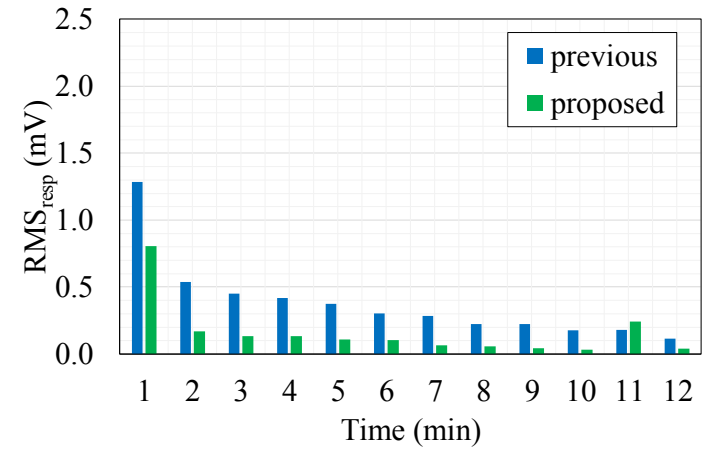

(a) Subject \#A (BMI 22.0)

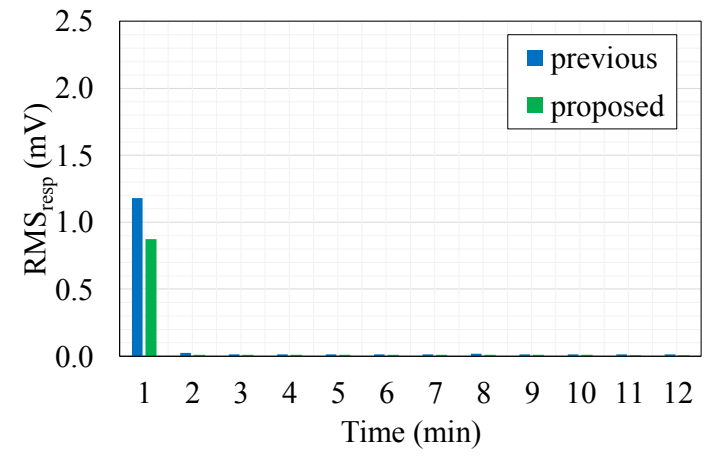

(c) Subject \#C (BMI 28.6)

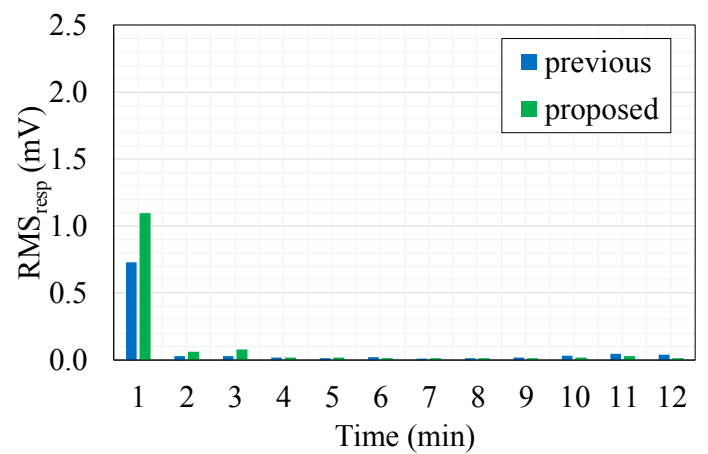

(b) Subject \#B (BMI 26.4)

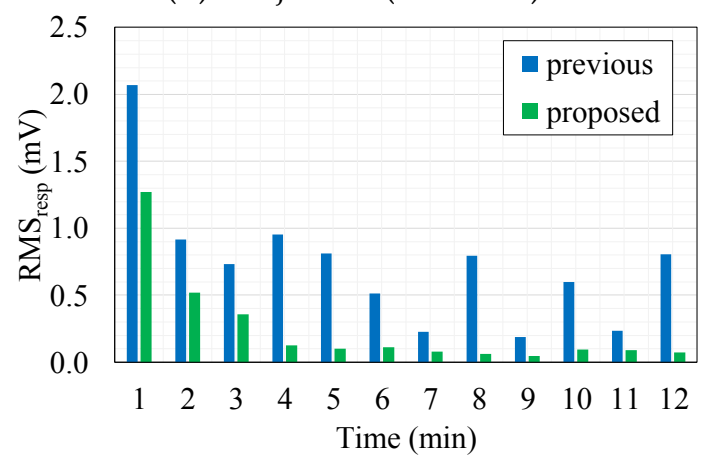

(d) Subject \#D (BMI 20.7)

Figure 8. Minute-by-minute transitions of the root mean square voltage ( $\mathrm{RMSV}_{\text {resp) }}$ extracted from cECG recordings measured with the previous AFE (blue) or the proposed AFE (green) in each subject. (a) Subject \#A (BMI 22.0). (b) Subject \#B (BMI 26.4). (c) Subject \#C (BMI 28.6). (d) Subject \#D (BMI 20.7).

\subsection{Measurements of cEMG in a Low-Humidity Environment}

Figure 9 shows example of EMG $\mathrm{EP}_{\text {ref }}$ and $\mathrm{cEMG}$ recordings measured with the previous and the proposed AFE under low-humidity conditions for subject \#E. For both of the AFEs, electromyographic 
firings during the "elbow bended" period in the cEMG signals were synchronized with those in the simultaneously measured $\mathrm{EMG}_{\text {ref }}$ signals. However, at times around elbow bending $(t=0 \mathrm{~s})$ and elbow straightening $(t=10 \mathrm{~s})$, there was a specific difference between the two AFEs in terms of baseline stability. When the previous AFE was used, the baseline of cEMG fluctuated widely around these timings, whereas the baseline settled with the use of the proposed AEF. This superiority in the baseline stability of the proposed AFE in the cEMG signal was observed in all subjects. In addition, with the use of the proposed AFE, the undesirable DC component in the signal was close to 0 in all subjects.
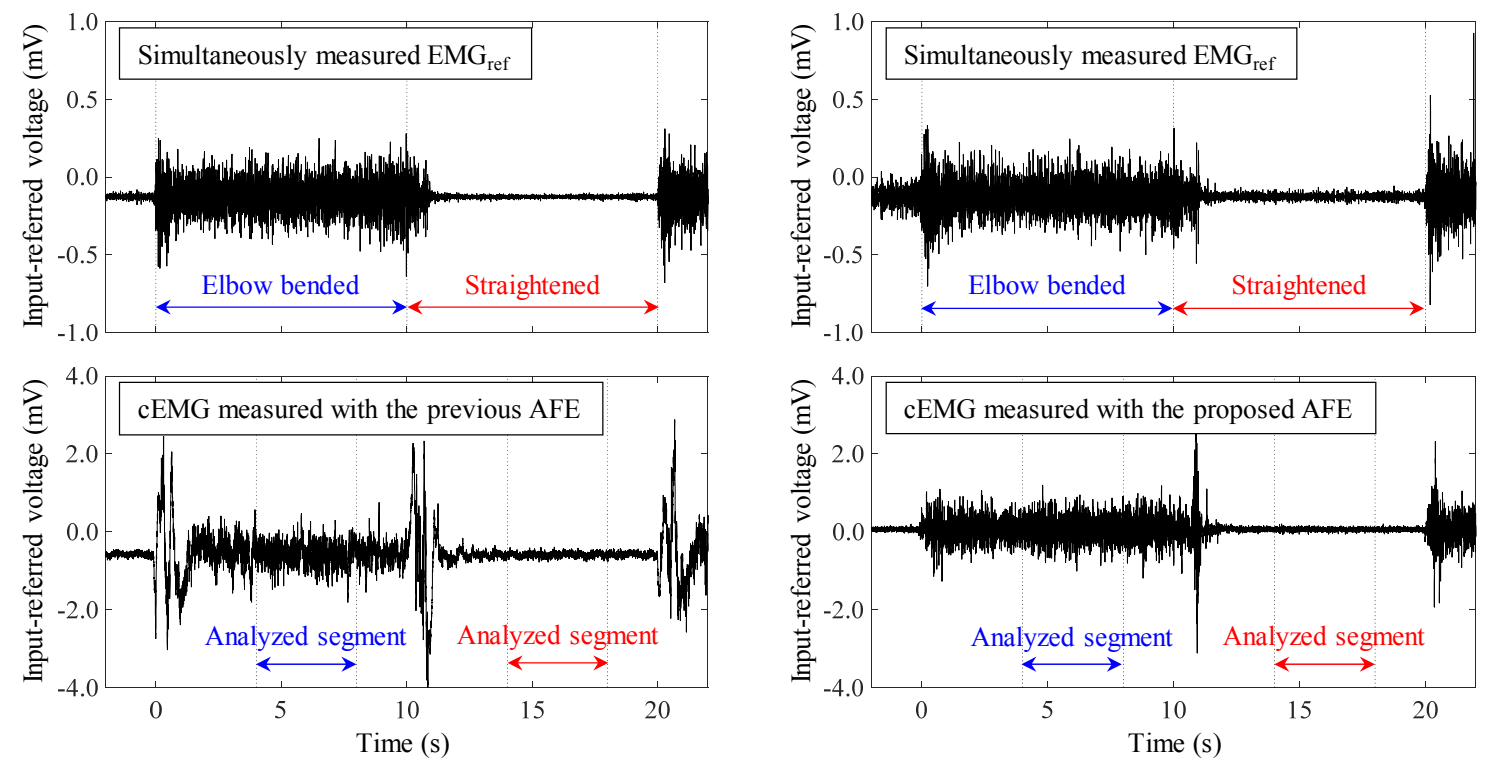

(a) Previous AFE

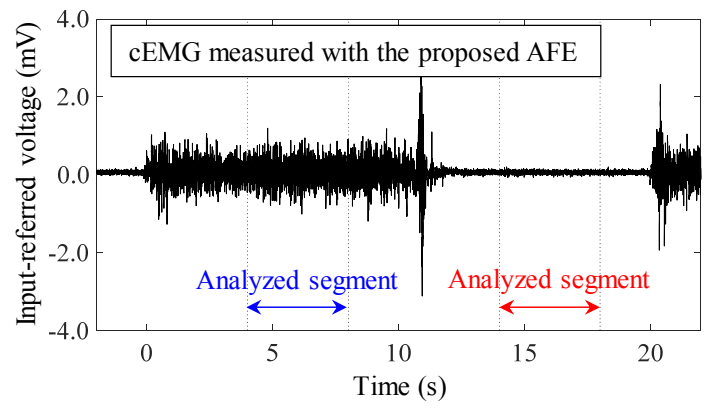

(b) Proposed AFE

Figure 9. Examples of simultaneously measured reference EMG $\left(E \mathrm{GG}_{\mathrm{ref}}\right)$ and $\mathrm{CEMG}$ through cotton cloth $\left(0.26 \mathrm{~mm}\right.$ thick) under conditions of low-humidity $\left(19 \%, 3.91 \mathrm{~g} / \mathrm{m}^{3}\right)$ from subject \#E using (a) the previous AFE and (b) the proposed AFE.

\subsection{Evaluation of cEMG Signals}

Figure 10 shows the DFT spectra of the analyzed segments in the cEMG signals depicted in Figure 9. When comparing the undesirable low-frequency components $(<20 \mathrm{~Hz})$ of the two AFEs, the spectral amplitudes with the proposed AFE were obviously smaller than those of the previous AFE, for both the elbow-bended segments (blue lines) and the elbow-straightened segments (red lines). On the other hand, when comparing the target frequency components $(20-500 \mathrm{~Hz})$, the spectral amplitudes with the proposed AFE for the elbow-bended segment were higher than that with the previous AFE. As for the elbow-straightened segment, the harmonic amplitudes of power-line frequency $(50 \mathrm{~Hz}$ in the east area of Japan) with the proposed AFE apparently decreased. These differences, which show the superiority of the proposed AFE, were consistent with the results shown in Figure 9, and were common in all subjects.

Figure 11 shows a comparison of the SNR of cEMG of the two AFEs. As shown in Figure 11a, the SNR with the proposed AFE clearly increased in each subject. Consequently, by grouping the SNR data for all subjects together, a comparison of the SNR between the AFEs indicated significance $(p<0.01)$ as shown in Figure 11b. These results are consistent with the results of the DFT spectra in Figure 10, which showed larger amplitudes in the frequency passband for the elbow-bended segment and smaller amplitudes for the elbow-straightened segment with the proposed AFE. 


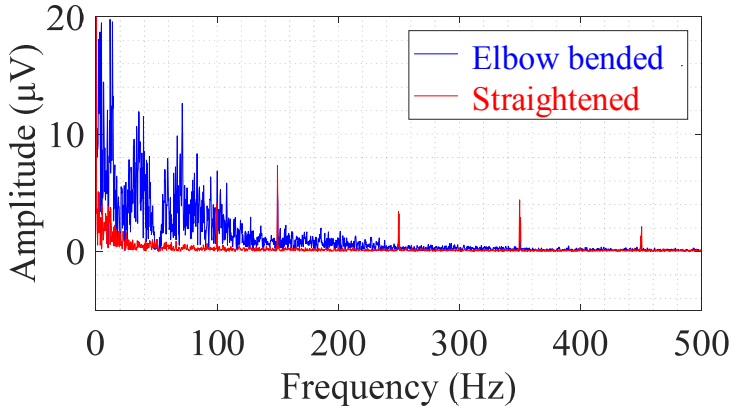

(a) Previous AFE

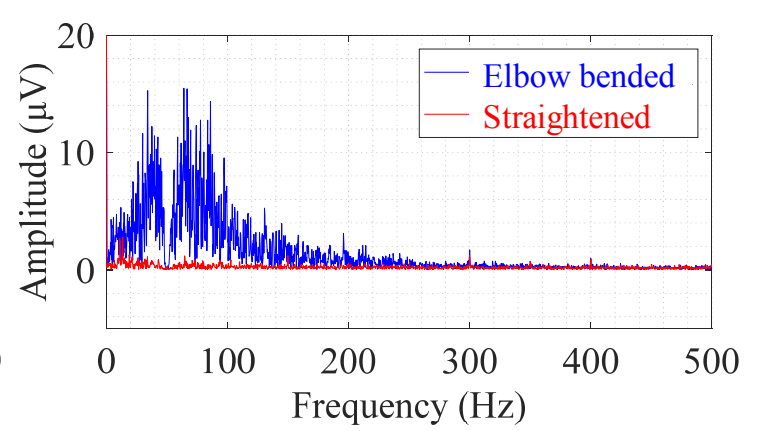

(b) Proposed AFE

Figure 10. Digital Fourier transform (DFT) spectra for cEMG recordings in Figure 9 obtained from subject \#E using (a) the previous AFE and (b) the proposed AFE. The blue line corresponds to the spectra for "Elbow bended" segments, and the red line corresponds to that for "Elbow straightened" segments.

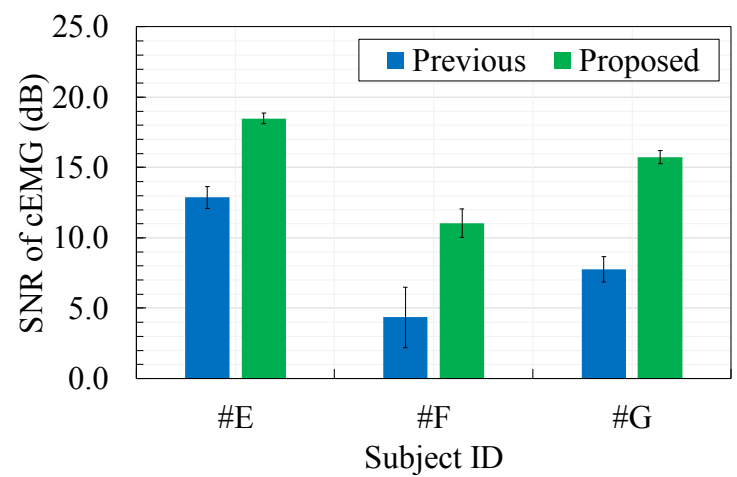

(a) In each subject

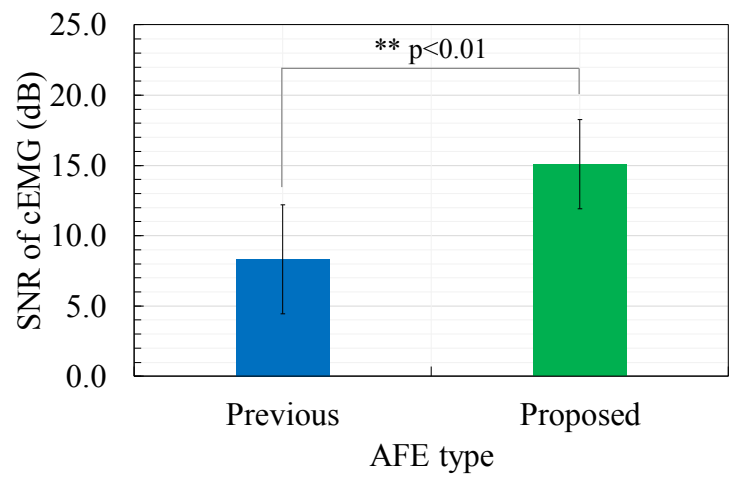

(b) For data pooled all together

Figure 11. Comparison of the signal-to-noise ratio (SNR) of recorded cEMG between the previous and proposed AFEs: (a) Comparison for each subject, (b) Comparison for data gathered from all subjects.

\section{Discussion}

The results depicted in Figures 6-11, confirm the superiority of the proposed AFE, which can be attributed to its three features: (F-1) voltage-dependent input impedance, (F-2) bandpass amplification, (F-3) stray capacitance reduction. We discuss the results in terms of the three features in the following subsections.

\subsection{Significance of Voltage-Dependent Input Impedance}

A comparison of the transient response of the cECG baseline shown in Figure 7a,b indicates that the proposed AFE has an advantage in its quick discharge capability owing to the voltage-dependent input impedance. In low-humidity conditions and the use of clothing made of chemical fiber in the skin-electrode coupling in CBM, our body and clothing are easily be electrically charged. Given a coupling charge between the skin and electrode for the measurement is $Q_{C}$ at the beginning of CBM, the coupling with capacitance $C_{C}$ generates DC voltage $V_{C}=Q_{C} / C_{C}$. Therefore, any new formation of the coupling, for instance, by lying down on the in-bed electrode during cECG measurements, can incur a large-magnitude input voltage $\left(>\left| \pm V_{t h r}\left(1+R_{b 3} / R_{h}\right)\right|\right)$ to the AFE of the measurement system. Similarly, an increase of $Q_{C}$, for instance, by friction caused by bending or straightening motions in cEMG measurements, can also produce a large-magnitude input. Therefore, because of the lower input impedance of the proposed AFE against the large-magnitude input $V_{C}$, the BR times were shorter for subjects \#A and \#D, as shown in Figure $7 \mathrm{~b}$ and Table 4 . For the same reason, moderate amplitude in the cEMG signal was also attained at the beginning of the bending motion, as shown in Figure $9 \mathrm{~b}$. In addition, in regard to the BR times for subject \#B and \#C, the DC voltage $V_{C}$ 
can be transformed to Equation (12) using the coupling distance $d_{C}$, coupling dielectric constant $\varepsilon_{C}$, and coupling area $A_{C}$ as follows:

$$
V_{C}=\frac{Q_{C}}{C_{C}}=\frac{Q_{C}}{\varepsilon_{C} A_{C}} d_{C}
$$

According to Equation (12), a small $d_{C}$ resulting from a large BMI (i.e., large coupling pressure) can result in small $V_{C}$ input to the AFE. In the case where the magnitude of $V_{C}$ is smaller than $\left| \pm V_{t h r}\left(1+R_{b 3} / R_{h}\right)\right|$, the input impedance of the proposed AFE is comparable to that of the previous AFE, leading to BR times in the same range in subjects \#B and \#C, as seen in Table 4.

When considering the fluctuation of $V_{C}$, we can derive Equation (13) by differentiating Equation (12) regarding $\varepsilon_{C}$ and $A_{C}$ as constants.

$$
\frac{d V_{C}(t)}{d t}=\frac{1}{\varepsilon_{C} A_{C}}\left(\frac{d Q_{C}(t)}{d t} d_{C}(t)+Q_{C}(t) \frac{d d_{C}(t)}{d t}\right)
$$

While the first member in Equation (13) represents the discharging process of $Q_{C}$ associated with BR time, the second member corresponds to the fluctuation caused by the change in $d_{C}$ such as the regulated breathing motion executed during cECG measurements. We can see that the second member is proportional not only to change in $d_{C}$ but also to $Q_{C}$ at the time. Therefore, residue of $Q_{C}$ resulting from the discharge can affect $\mathrm{RMSV}_{\text {resp }}$, which reflects the amplitude of disturbance caused by respiratory motion in cECG signals. In Figure $8 a, d$, compared with Figure $8 b, c$, larger values of $\mathrm{RMSV}_{\text {resp }}$ were obtained during 2-12 min periods. Presumably, these were because the lower coupling pressure of the healthy-weight-BMI subjects, \#A and \#D, resulted in a longer discharge process and in larger residue of $Q_{C}(t)$ in each minute. Comparison of the $\mathrm{RMSV}_{\text {resp }}$ values in subject \#A and \#D for the two AFEs shows the superior capability of the proposed AFE for quick discharge at low coupling pressure.

The oscillatory fluctuations observed in the cEMG signal (shown in Figure 9a) at the beginning of elbow bending and elbow straightening have the potential for resonance phenomena. As noted in Section 2 and in the literature [43], series connection of capacitive coupling with $C_{C}$ and $\mathrm{BVF}_{\mathrm{cf}}$ (i.e., the previous AFE) can cause resonant ringing at a frequency $f_{R S}$, as shown in Equation (14):

$$
f_{R S}=\frac{1}{2 \pi \sqrt{C_{C} C_{a 3} R_{a 1} R_{a 2}}}
$$

Given $C_{C}$ is $1.0 \mathrm{pF}$, assigning values in Table 1 to $C_{a 3}, R_{a 1}$ and $R_{a 2}$ leads to $f_{R S} \cong 0.16 \mathrm{~Hz}$. Though this frequency does not correspond with the actual frequency observed at the beginnings of the motion, they can be a ringing response of the high-pass filter (DC suppression circuit) in the measurement system (in Figure 4) against large stepwise input caused by the resonance. The undesirably large amplitudes in the low frequency region $(<10 \mathrm{~Hz})$ in both spectrums, shown in Figure 10a are also attributable to the resonance. The proposed AFE also has an advantage in terms of preventing resonance.

\subsection{Usefullness of Bandpass Amplification in AFE}

Comparison of the baseline in the cEMG signal in Figure 9a,b suggests another advantage of the proposed AFE in bandpass amplification. The baseline in Figure $9 \mathrm{a}$ is biased about $-0.7 \mathrm{mV}$ with the use of the previous AFE, whereas that in Figure 9 was vanishingly biased with the proposed AFE. This small bias is probably due to unequal gains in the proposed AFE for the DC component and for the components with the target frequencies $(20-500 \mathrm{~Hz})$. We can confirm that the gain for the DC component is $0 \mathrm{~dB}$ by observing Figure 2 and by assigning zero to $f$ in Equation (6). On the other hand, the gain for the components with the frequencies of interest is $20 \mathrm{~dB}$ in the proposed AFE but it is $0 \mathrm{~dB}$ in the previous AFE. Consequently, even when both measurement systems have the same total gain (i.e., $60 \mathrm{~dB}$ ) for the components with the frequency of concern, the relative magnitude of the DC component decreases in the system with the proposed AFE. Similar logic can be applied to the 
components with non-DC frequencies of no concern. Smaller amplitudes in lower frequency $(<20 \mathrm{~Hz})$ in the spectrum shown in Figure 10b are consistent with this logic. Furthermore, generally speaking, limiting the frequency band reduces thermal noise. Therefore, the bandpass feature of the proposed AFE was considered to be an important factor in the higher SNR in cEMG signal, as shown in Figure 11.

\subsection{Effect of Stray Capacitance Reduction}

Comparison of the R-wave amplitudes in Figure $6 c$,d suggests the presence of difference in input impedance between the two AFEs. As noted in previous research [19], stray capacitance between the measuring electrode and circuit ground in CBM can cause attenuation of R-wave amplitude. Consequently, larger R-wave amplitudes in Figure $6 \mathrm{~d}$, imply less stray capacitance in the input impedance, are attributable to $C_{n}$ being introduced only in the proposed AFE. Similarly, larger amplitudes of cEMG in the spectrum for the elbow-bended segment in Figure 10b are also due to reduced stray capacitance by $C_{n}$ in the proposed AFE. Note that the introduction of $C_{n}$ in the previous AFE does not reduce stray capacitance because compensating current is not produced due to no potential difference between the output and input nodes of the voltage follower. Hence, a change in AFE type from a voltage follower to a non-inverting amplifier is also necessary for the introduction of $C_{n}$.

\section{Conclusions}

This study proposed a novel AFE that has three features, which include voltage-dependent input impedance, bandpass amplification, and stray capacitance reduction. With a view to applying the AFE to CBMs, the three features were separately investigated in a schematic and mathematical manner. Measurements of cECG or cEMG using the AFE were performed under low-humidity conditions (below 35\% relative humidity) for a total of seven human subjects. Performance evaluation of the AFE revealed the following: (1) The proposed AFE in cECG measurements with $1.70 \mathrm{~mm}$ thick clothing reduced the BR time and RMSV $\mathrm{V}_{\text {resp }}$ for healthy-weight-BMI subjects, and increased the R-wave amplitude for overweight-BMI subjects. (2) The proposed AFE in cEMG measurements of biceps brachii muscle yielded stable electromyographic waveforms without a visibly biased baseline for all subjects and a significant $(p<0.01)$ increase in SNR. These results indicate that the proposed AFE can provide a feasible balance between sensitivity and stability in the CBM, and could be a versatile replacement for conventional voltage followers used in CBMs.

Author Contributions: Conceptualization, H.N. and A.U.; methodology, H.N. and A.U.; software, H.N.; validation, H.N. and A.U.; formal analysis, H.N.; investigation, H.N., Y.S. and A.U.; resources, H.N., Y.S., H.I. and A.U.; data curation, H.N. and A.U.; writing-original draft preparation, H.N.; writing-review and editing, A.U.; visualization, H.N.; supervision, A.U.; project administration, A.U.; funding acquisition, A.U. All authors have read and agreed to the published version of the manuscript.

Funding: This research was supported in part by SECOM Science and Technology Foundation and in part by Private University Research Branding Project supported by MEXT, Japan.

Conflicts of Interest: The authors declare no conflict of interest.

\section{References}

1. Majumder, S.; Aghayi, E.; Noferesti, M.; Memarzadeh-Tehran, H.; Mondal, T.; Pang, Z.; Deen, M.J. Smart Homes for Elderly Healthcare-Recent Advances and Research Challenges. Sensors 2017, 17, 2496. [CrossRef] [PubMed]

2. Habibzadeh, H.; Soyata, T. Toward uniform smart healthcare ecosystems: A survey on prospects, security, and privacy considerations. In Connected Health in Smart Cities, 1st ed.; Saddik, A.E., Hossain, M.S., Kantarci, B., Eds.; Springer: Cham, Switzerland, 2020; pp. 75-112.

3. Tian, S.; Yang, W.; Le Grange, J.M.; Wang, P.; Huang, W.; Ye, Z. Smart healthcare: Making medical care more intelligent. Glob. Health J. 2019, 3, 62-64. [CrossRef] 
4. Laplante, P.A.; Laplante, N. The internet of things in healthcare: Potential applications and challenges. It Prof. 2016, 18, 2-4. [CrossRef]

5. Islam, S.M.R.; Kwak, D.; Humaun Kabir, M.D.; Hossain, M.; Kwak, K.-S. The internet of things for health care: A comprehensive survey. IEEE Access 2015, 3, 678-708. [CrossRef]

6. Pantelopoulos, A.; Bourbakis, N.G. A survey on wearable sensor-based systems for health monitoring and prognosis. IEEE Trans. Syst. ManCybern. Part C 2010, 40, 1-12. [CrossRef]

7. Baig, M.M.; Afifi, S.; GholamHosseini, H.; Mirza, F. A systematic review of wearable sensors and IoT-based monitoring applications for older adults - a focus on ageing population and independent living. J. Med. Syst. 2019, 43, 233. [CrossRef]

8. Yang, G.; Xie, L.; Mäntysalo, M.; Chen, J.; Tenhunen, H.; Zheng, L.-R. Bio-patch design and implementation based on a low-power system-on-chip and paper-based inkjet printing technology. IEEE Trans. Inf. Technol. Biomed. 2012, 16, 1043-1050. [CrossRef]

9. Anliker, U.; Ward, J.A.; Lukowicz, P.; Troster, G.; Dolveck, F.; Baer, M.; Keita, F.; Schenker, E.B.; Catarsi, F.; Coluccini, L.; et al. AMON: A wearable multiparameter medical monitoring and alert system. IEEE Trans. Inf. Technol. Biomed. 2004, 8, 415-427. [CrossRef]

10. Poon, C.C.Y.; Wong, Y.M.; Zhang, Y.-T. M-Health: The Development of Cuff-less and Wearable Blood Pressure Meters for Use in Body Sensor Networks. In Proceedings of the 2006 IEEE/NLM Life Science Systems and Applications Workshop, Bethesda, MD, USA, 13-14 July 2006.

11. Torfs, T.; Leonov, V.; Hoof, C.V.; Gyselinckx, B. Body-Heat Powered Autonomous Pulse Oximeter. In Proceedings of the IEEE Sensors 2006 (EXCO), Daegu, Korea, 22-25 October 2006; pp. 427-430.

12. Poh, M.-Z.; Swenson, N.C.; Picard, R.W. Motion-tolerant magnetic earring sensor and wireless earpiece for wearable photoplethysmography. IEEE Trans. Inf. Technol. Biomed. 2010, 14, 786-794. [CrossRef]

13. Zheng, Y.; Leung, B.; Sy, S.; Zhang, Y.; Poon, C.C.Y. A Clip-free Eyeglasses-based Wearable Monitoring Device for Measuring Photoplethysmograhic Signals. In Proceedings of the 34th Annual International Conference of the IEEE EMBS, San Diego, CA, USA, 28 August-1 September 2012; pp. 5022-5025.

14. Scilingo, E.P.; Gemignani, A.; Paradiso, R.; Taccini, N.; Ghelarducci, B.; Rossi, D.D. Performance evaluation of sensing fabrics for monitoring physiological and biomechanical variables. IEEE Trans. Inf. Technol. Biomed. 2005, 9, 345-352. [CrossRef]

15. Paradiso, R.; Loriga, G.; Taccini, N. A wearable health care system based on knitted integrated sensors. IEEE Trans. Inf. Technol. Biomed. 2005, 9, 337-344. [CrossRef] [PubMed]

16. Pacelli, M.; Loriga, G.; Taccini, N.; Paradiso, R. Sensing Fabrics for Monitoring Physiological and Biomechanical Variables: E-textile Solutions. In Proceedings of the 2006 3rd IEEE/EMBS International Summer School on Medical Devices and Biosensors, Cambridge, MA, USA, 4-6 September 2006.

17. Pandian, P.S.; Mohanavelu, K.; Safeer, K.P.; Kotresh, T.M.; Shakunthala, D.T.; Gopal, P.; Padaki, V.C. Smart vest: Wearable multi-parameter remote physiological monitoring system. Med. Eng. Phys. 2008, 30, 466-477. [CrossRef] [PubMed]

18. Lopez, A.; Richardson, P.C. Capacitive electrocardiographic and bioelectric electrodes. IEEE Trans. Biomed. Eng. 1969, BME-16, 99. [CrossRef] [PubMed]

19. Ueno, A.; Akabane, Y.; Kato, T.; Hoshino, H.; Kataoka, S.; Ishiyama, Y. Capacitive sensing of electrocardiographic potential through cloth from the dorsal surface of the body in a supine position: A preliminary study. IEEE Trans. Biomed. Eng. 2007, 54, 759-766. [CrossRef] [PubMed]

20. Linz, T.; Gourmelon, L.; Langereis, G. Contactless EMG Sensors Embroidered onto Textile. In Proceedings of the 4th International Workshop on Wearable and Implantable Body Sensor Networks (BSN 2007), Aachen, Germany, 26-28 March 2007; pp. 29-34.

21. Ueno, A.; Yamaguchi, T.; Iida, T.; Fukuoka, Y.; Uchikawa, Y.; Noshiro, M. Feasibility of capacitive sensing of surface electromyographic potential through cloth. Sens. Mater. 2012, 24, 335-346.

22. Roland, T.; Amsüssb, S.; Russoldb, M.F.; Wolfa, C.; Baumgartnera, W. Capacitive sensing of surface EMG for upper limb prostheses control. Procedia Eng. 2016, 168, 155-158. [CrossRef]

23. Matsuo, T.; Iinuma, K.; Esashi, M. A barium-titanate-ceramics capacitive-type EEG electrode. IEEE Trans. Biomed. Eng. 1973, BME-20, 299-300. [CrossRef]

24. Chi, Y.M.; Wang, Y.-T.; Wang, Y.; Maier, C.; Jung, T.-P.; Cauwenberghs, G. Dry and noncontact EEG sensors for mobile brain-computer interfaces. IEEE Trans. Neural Syst. Rehabil. Eng. 2012, 20, 228-235. [CrossRef] 
25. Baek, H.J.; Lee, H.J.; Lim, Y.G.; Park, K.S. Conductive polymer foam surface improves the performance of a capacitive EEG electrode. IEEE Trans. Biomed. Eng. 2012, 59, 3422-3431. [CrossRef]

26. Kato, T.; Ueno, A.; Kataoka, S.; Hoshino, H.; Ishiyama, Y. An Application of Capacitive Electrode for Detecting Electrocardiogram of Neonates and Infants. In Proceedings of the 28th Annual International Conference of IEEE EMBS, New York, NY, USA, 31 August-3 September 2006; pp. 916-919.

27. Takano, M.; Ueno, A. Noncontact in-bed measurements of physiological and behavioral signals using an integrated fabric-sheet sensing scheme. IEEE J. Biomed. Health Inf. 2019, 23, 618-630. [CrossRef]

28. Kim, K.K.; Lim, Y.K.; Park, K.S. Common Mode Noise Cancellation for Electrically Non-Contact ECG Measurement System on a Chair. In Proceedings of the 2005 IEEE Engineering in Medicine and Biology Society 27th Annual Conference, Shanghai, China, 1-4 September 2005; pp. 5881-5883.

29. Aleksandrowicz, A.; Leonhardt, S. Wireless and non-contact ECG measurement system-The "Aachen SmartChair". Acta Polytech. 2007, 47, 68-71.

30. Kim, K.K.; Lim, Y.K.; Park, K.S. The Electrically Non-contacting ECG Measurement on the Toilet Seat Using the Capacitively-coupled Insulated Electrodes. In Proceedings of the 26th Annual International Conference of the IEEE EMBS, San Francisco, CA, USA, 1-5 September 2004; pp. 2375-2378.

31. Lim, Y.K.; Kim, K.K.; Park, K.S. The ECG Measurement in the Bathtub Using the Insulated Electrodes. In Proceedings of the 26th Annual International Conference of the IEEE EMBS, San Francisco, CA, USA, 1-5 September 2004; pp. 2383-2385.

32. Leonhardt, S.; Aleksandrowicz, A. Non-Contact ECG Monitoring for Automotive Application. In Proceedings of the 5th International Summer School and Symposium on Medical Devices and Biosensors, Hong Kong, China, 1-3 June 2008; pp. 183-185.

33. Wartzek, T.; Eilebrecht, B.; Lem, J.; Lindner, H.-J.; Leonhardt, S.; Walter, M. ECG on the road: Robust and unobtrusive estimation of heart rate. IEEE Trans. Biomed. Eng. 2011, 58, 3112-3120. [CrossRef] [PubMed]

34. Schumm, J.; Setz, C.; Bächlin, M.; Bächler, M.; Arnrich, B.; Tröster, G. Unobtrusive physiological monitoring in an airplane seat. Pers. Ubiquitous Comput. 2010, 14, 541-550. [CrossRef]

35. Wartzek, T.; Elfring, R.; Janssen, A.; Eilebrecht, B.; Walter, M.; Leonhardt, S. On the Way to a Cable Free Operating Theater: An Operating Table with Integrated Multimodal Monitoring. In Proceedings of the 2011 Computing in Cardiology, Hangzhou, China, 18-21 September 2011; pp. 129-132.

36. Wartzek, T.; Lammersen, T.; Eilebrecht, B.; Walter, M.; Leonhardt, S. Triboelectricity in capacitive biopotential measurements. IEEE Trans. Biomed. Eng. 2011, 58, 1268-1277. [CrossRef] [PubMed]

37. Chi, Y.M.; Jung, T.-P.; Cauwenberghs, G. Dry-contact and noncontact biopotential electrodes: Methodological review. IEEE Rev. Biomed. Eng. 2010, 3, 106-119. [CrossRef]

38. Fukuyama, Y.; Suzuki, R.; Takayama, S.; Ueno, A. Multi-layered Fabric Electrode for Movement Artifact Reduction in Capacitive ECG Measurement. In Proceedings of the 35th Annual International Conference of IEEE (EMBS), Osaka, Japan, 3-7 July 2013; pp. 555-558.

39. Thakor, N.V.; Webster, J.G. Ground-free ECG recording with two electrodes. IEEE Trans. Biomed. Eng. 1980, BME-27, 699-704. [CrossRef]

40. Chi, Y.M.; Maier, C.; Cauwenberghs, G. Ultra-high input impedance, low noise integrated amplifier for noncontact biopotential sensing. IEEE Trans. Emerg. Sel. Top. Circuits Syst. 2011, 1, 526-535. [CrossRef]

41. Takano, M.; Yamagishi, S.; Ohmuta, T.; Fukuoka, Y.; Ueno, A. Non-contact simultaneous measurements of electrocardiogram and respiratory movements using capacitive sheet electrodes. Adv. Biomed. Eng. 2017, 6, 28-36. [CrossRef]

42. Borelli, G.; Bonnet, J.J.; Hernandez, Y.R.; Matsuda, K.; Damerau, J. Spectral-distance-based detection of EMG activity from capacitive measurements. IEEE Sens. J. 2018, 18, 8502-8509. [CrossRef]

43. Nakamura, H.; Kato, Y.; Ueno, A. Design and Validation of Front-End Voltage Follower for Capacitive Electrocardiogram Measurement Using Bootstrapping Technique. In Proceedings of the 40th Annual International Conference of the IEEE (EMBS), Honolulu, HI, USA, 18-21 July 2018; pp. 5780-5783. 
44. Chi, Y.M.; Cauwenberghs, G. Micropower Non-contact EEG Electrode with Active Common-Mode Noise Suppression and Input Capacitance Cancellation. In Proceedings of the 31st Annual International Conference of the IEEE (EMBS), Minneapolis, MN, USA, 2-6 September 2009; pp. 4218-4221.

45. Takano, M.; Komiya, H.; Ueno, A. Stability Improvement and Noise Suppression in Non-Contact In-Bed Electrocardiogram Measurement Using Laminated Feedback Electrode. In Proceedings of the 2017 IEEE Biomedical Circuits and Systems Conference, Turin, Italy, 19-21 October 2017; pp. 364-367.

(C) 2020 by the authors. Licensee MDPI, Basel, Switzerland. This article is an open access article distributed under the terms and conditions of the Creative Commons Attribution (CC BY) license (http://creativecommons.org/licenses/by/4.0/). 